\title{
MATERIAIS AUDIOVISUAIS DIDÁTICOS E EDUCAÇÃO SEXUAL NA ESCOLA: UMA PESQUISA NOS ACERVOS VIDEOGRÁFICOS DO MINISTÉRIO DA EDUCAÇÃO E CULTURA E MINISTÉRIO DA SAÚDE DO GOVERNO BRASILEIRO
}

\author{
Vagner Matias do Prado, Arilda Inês Miranda Ribeiro, Luciana Cristine Fazano \\ Universidade Estadual Paulista Júlio de Mesquita Filho - UNESP; Depto de Educação; vmp ef@yahoo.com.br. Apoio: FAPESP - \\ Fundação de Amparo à Pesquisa do Estado de São Paulo
}

\section{RESUMO}

O presente artigo aborda as diferenças sexuais como problemática de pesquisa. Parte-se do pressuposto de que o trabalho sobre educação sexual nas escolas deve ser efetivado para além da dimensão biológica, atentando para os aspectos históricos, culturais, sociais e políticos que perpassam o tema e influem na construção de identidades culturais. Dessa maneira, materiais de apoio pedagógico para implementar essas intervenções são de extrema relevância para o trabalho docente, dentre eles, os de formato audiovisual se mostram produtivos. O objetivo proposto consistiu em realizar um levantamento sobre vídeos educativos junto aos ministérios da Educação e Cultura e da Saúde do Governo Federal brasileiro com o intuito de confeccionar uma lista contendo títulos de materiais que poderiam subsidiar a ação pedagógica. Os resultados aferidos demonstram uma tímida iniciativa governamental para a confecção desses materiais, mesmo a sexualidade se configurando como um tema transversal a ser incluído no currículo escolar.

Palavras-chave: Educação Sexual, Identidades LGBTTT, Materiais Audiovisuais.

\section{AUDIOVISUAL TEACHING MATERIALS AND SEX EDUCATION IN SCHOOLS: A SURVEY OF THE VIDEOGRAPHER COLLECTIONS OF THE DEPARTMENT OF EDUCATION, CULTURE AND DEPARTMENT OF HEALTH OF THE BRAZILIAN GOVERNMENT}

\begin{abstract}
This article discusses sex differences as a research issue. It starts from the assumption that the work on sex education in schools should be effected beyond the biological dimension, focusing on the historical, cultural, social and political aspects that underlie the issue and influence the construction of cultural identities. In this manner, teaching support materials to implement these interventions are very important for the educational work, among them, the audiovisual materials are very productive. The proposed goal was to conduct a survey of educational videos with the Departments of Education, Culture and Health of the Brazilian Government in order to make a list containing titles of materials that could subsidize the pedagogical action. The measured results show a timid government initiative for the production of these materials, even sexuality shaping up as a crosscutting theme to be included as a school subject.
\end{abstract}

Keywords: Sex Education, LGBTTT Identity, Audiovisual Materials. 


\section{INTRODUÇÃO'}

A sexualidade é assunto que desperta curiosidades, confronta valores, desestabiliza certezas e aprisiona identidades. Ao contrariar as teorias biológicas que tentam nos direcionar unicamente para aspectos anátomo-fisiológicos de sua constituição, a abordagem do tema nos convida a analisar os diferentes discursos que a constitui. A sexualidade é corpo, é cultura, é expressão, é política.

Ao fundamentarmos nossas argumentações em estudos inspirados no pósestruturalismo francês compreendemos que a sexualidade, como categoria política, se encontra intimamente relacionada com a atribuição de marcas identitárias aos sujeitos (BRITZMAN, 2001; FOUCAULT, 1985; FURLANI, 2008; LOURO, 2001). Essa "política de identidades" se encontra inscrita em uma lógica de poder que pressupõe a heterossexualidade como natural, relegando outras possíveis identidades sexuais ao domínio da "anormalidade" (BUTLER, 2008). Nesse sentido, a heterossexualidade é enaltecida pelo social e Lésbicas, Gays, Bissexuais, Travestis, Transexuais e Transgênicos (LGBTTT) são punidos com o não reconhecimento jurídico, marginalização, preconceito e violência.

Ao partirmos de pressupostos voltados para a instrumentalização de educadores, nos lançamos em reflexões para aproximar a linguagem audiovisual como recurso didáticometodológico para o desenvolvimento de trabalhos de educação sexual nas escolas. Baseados nos trabalhos de Ferrés (1996), Fischer (2002), Kelner (2002) e Magaldi (2006),

$1 \quad 0$ presente artigo baseia-se na Dissertação de Mestrado "Sexualidade(S) em cena: as contribuições do discurso audiovisual para a problematização das diferenças no espaço escolar", de autoria de Vagner Matias do Prado, defendida em maio de 2010 junto ao Programa de PósGraduação em Educação da Faculdade de Ciências e Tecnologia da UNESP sob orientação da Profa Dra Arilda Inês Miranda Ribeiro. A pesquisa contou com o auxílio da CAPES - Coordenação de Aperfeiçoamento de Pessoal de Nível Superior e FAPESP - Fundação de Amparo à Pesquisa do Estado de São Paulo. argumentamos em favor da utilização de filmes que possam estabelecer um diálogo com a sexualidade a partir de uma ótica cultural, principalmente no que tange a problematização e reflexão sobre o reconhecimento social e político de sujeitos não heterossexuais.

\section{OBJETIVO}

Realizar um levantamento sobre materiais audiovisuais educativos sobre a temática da sexualidade, confeccionados por iniciativa governamental, que poderiam ser utilizados como recurso pedagógico ao trabalho de educação sexual.

\section{METODOLOGIA}

Através de uma pesquisa de caráter quantitativo, realizamos um levantamento de títulos de vídeos governamentais sobre a temática da sexualidade confeccionados pelo Ministério da Educação e Cultura (MEC) e Ministério da Saúde (MS) do governo brasileiro. O instrumento utilizado para a geração de dados foi a Rede Mundial de Computadores (internet) que possibilitou consultar os acervos videográficos encontrados junto aos web sites do MEC e do MS.

\section{RESULTADOS E DISCUSSÃO}

\section{Sobre os materiais didáticos videográficos do Ministério da Educação e Cultura}

Durante a pesquisa realizada junto ao

Ministério da Educação e Cultura (MEC), e através da utilização de um espaço em sua página da web para realizar buscas sobre conteúdos do site, percebemos que esse órgão federal não disponibiliza nenhum espaço para catalogação e divulgação de uma possível produção audiovisual sobre a temática da sexualidade. Contudo, é possível encontrar em suas páginas um link que nos direciona para um ambiente virtual, assinado pelo Governo Federal, denominado "Domínio Público". 
O Domínio Público se configura como uma "biblioteca virtual desenvolvida com softwares livres" (DOMÍNIO PÚBLICO, 2008). Ao "navegar" por suas páginas encontramos um espaço destinado a pesquisas sobre os conteúdos nele existentes. Nesse espaço é pedido que o "visitante" selecione o tipo de material que deseja consultar. A consulta pode ser realizada em 4 categorias: 1. Imagem; 2. Som; 3. Texto; ou 4. Vídeo.

De acordo com nossas intenções de pesquisa, realizamos uma busca de materiais na categoria denominada "Vídeo". Como resultado, o site nos disponibilizou uma série de materiais do projeto "TV Escola" categorizados por áreas temáticas de interesse. Ao consultar todas as categorias temáticas fornecidas, encontramos 5 vídeos que poderiam subsidiar o trabalho pedagógico em educação sexual, sendo que um desses materiais encontra-se dividido em três partes.

Dos vídeos selecionados, dois (2) se referem a temas específicos sobre sexualidade, tratando-se dos vídeos "Violência Sexual" e "Juventude e sexualidade", este último dividido em três partes. Os outros materiais selecionados não fazem referência específica a temática, mas poderiam ser utilizados para problematizar alguns de seus "encaminhamentos". Tratam-se dos vídeos "Mulheres - visão do esporte", que poderia ser utilizado para debates acerca das relações de gênero; "Viva a Diferença", para reflexões sobre inclusão e cidadania; e "Violência que Rola", que poderia ser utilizado para iniciar um debate escolar acerca da violência e como ela atinge sujeitos LGBTTT em sua vertente homofóbica. Sobre os anos de produção desses materiais, nenhuma referência foi encontrada.
QUADR01: Resultados da pesquisa por vídeos no site "Domínio Público"”

\begin{tabular}{|c|c|c|}
\hline $\begin{array}{c}\text { Categoria de } \\
\text { pesquisa }\end{array}$ & Área temática & Título \\
\hline TV Escola & Ética & $\begin{array}{c}\text { Violência Sexual } \\
\text { (Direitos Humanos) }\end{array}$ \\
\hline TV Escola & $\begin{array}{c}\text { Salto para o } \\
\text { futuro }\end{array}$ & $\begin{array}{c}\text { Juventude e } \\
\text { Sexualidade } \\
\text { (Ensino Médio: entre } \\
\text { jovens e estudantes) } \\
\text { partes: 1, 2 e 3 }\end{array}$ \\
\hline TV Escola & $\begin{array}{c}\text { Educação } \\
\text { Física }\end{array}$ & $\begin{array}{c}\text { Mulheres (Visões do } \\
\text { Esporte) }\end{array}$ \\
\hline TV Escola & $\begin{array}{c}\text { Escola/Educaç } \\
\text { ão }\end{array}$ & $\begin{array}{c}\text { Viva a Diferença } \\
\text { Violência que Rola } \\
\text { (Direitos Humanos) }\end{array}$ \\
\hline TV Escola & Ética &
\end{tabular}

Mesmo com a indicação governamental contida no Tema Transversal sobre Orientação Sexual dos Parâmetros Curriculares Nacionais (BRASIL, 1998) para a inserção da temática da sexualidade no currículo escolar, os resultados apresentados demonstram a escassez de movimentações do MEC para a elaboração de materiais audiovisuais didáticos que poderiam subsidiar essa discussão. Contudo, apesar das poucas referências encontradas, os vídeos "Juventude e Sexualidade (Ensino Médio: entre jovens e estudantes)" e "Mulheres (visão do esporte)" poderiam ser incluídos em ações pedagógicas comprometidas em problematizar as categorias "gênero" e "sexualidade" como construtoras de diversas desigualdades sociais. Nesse sentido, poder-se-ia contribuir para a análise crítica de como esses marcadores atuam para a legitimação de uma ordem social que justifica a inferioridade do gênero feminino, ou a "anormalidade" das identidades LGBTTT, em favor da manutenção de uma matriz cultural heterossexista, discriminatória e excludente.

\section{Sobre os materiais didáticos videográficos do Ministério da Saúde Nossas buscas sobre materiais governamentais junto ao Ministério da Saúde

Disponível em:
http://www.dominiopublico.gov.br/pesquisa/PesquisaObraFor
m.jsp Acesso em: 07. Outubro. 2008 .


(MS) nos direcionou ao web site da Biblioteca Virtual do Ministério da Saúde (MINISTÉRIO DA SAÚDE, 2008). A Biblioteca Virtual constitui-se em uma base de dados que nos permite realizar pesquisas utilizando descritores ou palavraschave, que devem ser digitadas em um espaço reservado à pesquisa. Os resultados das buscas são disponibilizados em três categorias de interesse: 1. Coleção de publicações; 2. Coleção de vídeos; 3. Portal de textos completos. Essas três categorias de organização do conteúdo do site são denominadas de "literatura técnicocientífica em saúde".

Dessa maneira, nos focamos em observar os resultados obtidos na pesquisa para a categoria "Coleção de Vídeos". Para a realização da busca foram utilizados alguns descritores que nos permitiram elaborar uma lista dos vídeos que fazem menção à sexualidade e as diferenças sexuais. Os descritores utilizados para a pesquisa foram: Sexualidade; Educação Sexual; Orientação Sexual; Preconceito Sexual; Homofobia; Sexo; Diversidade Sexual; Diferenças Sexuais; Transgêneros/Transgeneridades; Transexuais/Transexualidade;

Travestis/Travestilidade;

Intersexuais/Intersexualidade;

Hermafroditas; Homossexualidade;

Bissexualidade; Heterossexualidade. A escolha dos descritores foi realizada com base em termos evidenciados no transcorrer da fase bibliográfica da pesquisa ora apresentada.

Com os resultados da pesquisa elaboramos uma listagem com os títulos dos vídeos encontrados e seus respectivos anos de produção. Dentre os vídeos pesquisados em cada descritor, alguns resultados se mostraram repetidos devido a sua catalogação em mais de uma palavra chave. Para os descritores Diversidade Sexual; Diferenças Sexuais; Transexuais/Transexualidade; Bissexuais; Travestis/Travestilidade;
Transgêneros/Transgeneridade;

Intersexuais/Intersexualidade; Hermafroditas e Heterossexualidade, não foram encontrados nenhuma referência videográfica.

QUADRO 2: Resultados da pesquisa por vídeos no site "Biblioteca Virtual" do Ministério da Saúde ${ }^{3}$

\begin{tabular}{|c|c|c|}
\hline DESCRITOR & $\begin{array}{l}\text { QUANTI } \\
\text { DADE }\end{array}$ & TÍTULOS/ ANO DE PRODUÇÃO \\
\hline Sexualidade & 6 & $\begin{array}{l}\text { Sexo: informações que ajudam. Sexo: } \\
\text { uma questão de qualidade de vida. } 2000 \\
\text { Ficar por dentro! [s. d.] } \\
\text { Pare, pense, use: métodos contraceptivos. } \\
1990 \\
\text { Minha vida de João. } 2003 \\
\text { Adolescentes discutem sexualidade com a } \\
\text { sua turma: gravidez e anticoncepção na } \\
\text { adolescência. } 2005 \\
\text { Aparelho urinário, crescimento fetal } \\
\text { retardado, sexualidade na adolescência, } \\
\text { endometriose. } 1996\end{array}$ \\
\hline $\begin{array}{c}\text { Educação } \\
\text { Sexual }\end{array}$ & 6 & $\begin{array}{l}\text { Sexo: informações que ajudam. Sexo: } \\
\text { uma questão de qualidade de vida. } 2000 \\
\text { Gravidez na adolescência: quando a } \\
\text { menina troca as bonecas pelo bebê. } 1998 \\
\text { Reprodução humana: sistemas que } \\
\text { garantem a renovação da vida. } 1998 \\
\text { Reprodução humana. 1984? } \\
\text { Projeto amor à vida: educando pela paz. } \\
\text { 2001 } \\
\text { Repertório: prevenir é a solução. [s. d.] }\end{array}$ \\
\hline Sexo & 4 & $\begin{array}{l}\text { Métodos anticoncepcionais: sexo não } \\
\text { precisa ser sinônimo de gravidez. } 1998 \\
\text { Sexo: informações que ajudam. Sexo: } \\
\text { uma questão de qualidade de vida. } 2000 \\
\text { Gravidez na adolescência: quando a } \\
\text { menina troca as bonecas pelo bebê. } 1998 \\
\text { Adolescência: aprendendo a fazer sexo } \\
\text { seguro. } 1998\end{array}$ \\
\hline $\begin{array}{l}\text { Homossexualida } \\
\text { de }\end{array}$ & 2 & $\begin{array}{c}\text { Para que time ele joga? } 2002 \\
\text { Ritos e ditos de jovens gays. } 2002\end{array}$ \\
\hline $\begin{array}{c}\text { Preconceito } \\
\text { Sexual }\end{array}$ & 1 & Ritos e ditos de jovens gays. 2002 \\
\hline
\end{tabular}

Tratando-se de um órgão governamental ligado à área de saúde pública, é notável que a

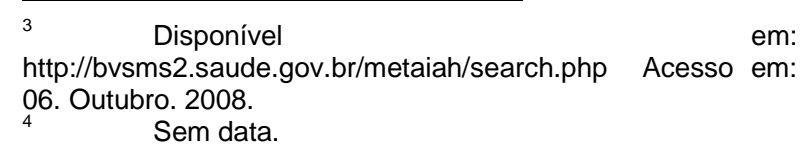


maior parte do material encontrado faça referência ao caráter biológico da sexualidade. Nesse sentido, temas como gravidez na adolescência, prevenção de doenças ou descrição dos aparelhos reprodutores são recorrentes. Os vídeos "Sexo informações que ajudam. Sexo: uma questão de qualidade de vida" (2000); "Ficar por dentro" ([s.d.]); "Adolescentes discutem sexualidade com a sua turma: gravidez e anticoncepção na adolescência" (2005); "Gravidez na adolescência: quando a menina troca as bonecas pelo bebê" (1998); "Reprodução humana: sistemas que garantem a renovação da vida" (1998); "Repertório: prevenir é a solução" ([s.d.]); "Métodos anticoncepcionais: sexo não precisa ser sinônimo de gravidez" (1998); e "Adolescência: aprendendo a fazer sexo seguro" (1998); "Reprodução humana" (1984); "Pense, pense: use métodos contraceptivos" (1990); e "Aparelho urinário, crescimento fetal retardado, sexualidade na adolescência, endometriose" (1996), são exemplos dessas produções. Para o vídeo "Projeto amor à vida: educando pela paz" (2001), informações sobre seu conteúdo não foram encontradas.

Entretanto, em comparação com o escasso material que pode ser encontrado via MEC, o MS se mostra produtivo na elaboração de materiais educativos audiovisual, inclusive no que se refere à elaboração de materiais que podem ser utilizados para problematizar as diferenças sexuais nas escolas. Dos vídeos encontrados na biblioteca virtual do MS, um propõe discussões sobre as questões de gênero: "Minha vida de João" (2003); e dois fazem menção especificamente às diferenças sexuais, inclusive explicitamente em seus títulos: "Pra que time ele joga?" e o filme "Ritos e ditos de jovens gays", ambos produzidos em 2002.

Embora nossa pesquisa tenha um caráter quantitativo, faz-se necessário, em pesquisas futuras, realizar uma análise detalhada do conteúdo desses materiais visando problematizar os discursos construtores dos saberes e verdades sobre a sexualidade que são divulgados a partir dessa tipologia de iniciativa "didática".

\section{CONCLUSÕES}

Embora materiais audiovisuais sobre sexualidades possam ser encontrados nas esferas governamentais, os resultados de nossa pesquisa evidenciaram a precariedade de pensamentos políticos voltados para a construção de materiais de apoio pedagógico que possibilitem desenvolver debates escolares acerca dos aspectos culturais e de marcação de diferenças sociais desencadeados pela construção de saberes sobre a sexualidade humana. Dos materiais produzidos que poderiam ser incluídos em ações pedagógicas para tal finalidade encontramos os vídeos "Pra que time ele joga?" (2002), "Ritos e ditos de jovens gays" (2002) e "Minha vida de João" (2003), assinados em parceria com o MS. Já o MEC se mostra insuficiente em relação à produção de materiais audiovisuais didáticos para subsidiar essas intervenções.

Nesse sentido, e seguindo orientações governamentais em favor dos direitos humanos, educacionais e sexuais (BRASIL, 1998; CONSELHO NACIONAL DE COMBATE À DISCRIMINAÇÃO, 2004), faz-se urgente problematizar o preconceito e discriminação que atingem sujeitos LGBTTT. Essa "educação para a cidadania" encontra na escola um ambiente propício para que ações democráticas e de reconhecimento das diferenças culturais se estabeleçam. Esforços despendidos em para problematizar a temática da sexualidade junto aos espaços de formação de educadores, bem como a elaboração de materiais didático-pedagógicos para que o trabalho de educação sexual se efetive nas escolas, devem ser colocados em pauta no âmbito das políticas públicas de 
formação e capacitação para a área da Educação.

\section{REFERÊNCIAS}

BRASIL. Parâmetros Curriculares Nacionais Temas Transversais: Orientação Sexual. Brasília: Secretaria de Educação Fundamental MEC/SEF, 1998.

BRITZMAN, D. Curiosidade, sexualidade e currículo. In: LOURO, G. L. (Org.). O corpo educado: pedagogias da sexualidade. 2.ed. Belo Horizonte: Autêntica, 2001. p. 83-111.

BUTLER, J. Cuerpos que importan: sobre los limites materiales y discursivos del "sexo". 2.ed. Buenos Aires: Paidós, 2008.

CONSELHO NACIONAL DE COMBATE À DISCRIMINAÇÃO. Brasil sem Homofobia: programa de combate à violência e à discriminação contra GLTB e promoção da cidadania homossexual. Brasília: Ministério da Saúde, 2004.

DOMÍNIO PÚBLICO. Biblioteca digital desenvolvida com Softwares livres. Disponível em:

$<$ http://www.dominiopublico.gov.br/pesquisa/Pesq uisaObraForm.jsp>. Acesso em: 07. Out. 2008.

FERRÉS, J. Vídeo e Educação. Porto Alegre: Artes Médicas, 1996.

FISCHER, R. M. B. O dispositivo pedagógico da mídia: modos de educar na (e pela) TV. Educação e Pesquisa, v. 28, n. 1, 2002, p. 151162.

FOUCAULT. M. História da sexualidade: a vontade do saber. 7.ed. Rio de Janeiro: Graal, 1985.

FURLANI, J. (Org.). Educação Sexual na Escola: equidade de gênero, livre orientação sexual e igualdade étnico-racial numa proposta de respeito as diferenças. Florianópolis: UDESC (Fundação Universidade do Estado de Santa Catarina), 2008.

KELNER, D. Lendo imagens criticamente: em direção a uma pedagogia pós-moderna. In: SILVA, T. T. (Org.). Alienígenas na sala de aula: uma introdução aos estudos culturais em educação. $4^{\mathrm{a}}$ ed. Petrópolis: Vozes, 2002. p. 104131.

LOURO, G. L. (Org.). O corpo educado: pedagogias da sexualidade. 2.ed. Belo Horizonte: Autêntica, 2001.
MAGALDI, S. A TV como objeto de estudo na Educação: idéias e práticas. In: FISCHER, R. M. B. Televisão \& Educação: fruir e pensar a TV. 3.ed. Belo Horizonte: Autêntica, 2006. p. 111143.

MINISTÉRIO DA EDUCAÇÃO E CULTURA. Site oficial. Disponível em: <http://portal.mec.gov.br>. Acesso em: 07. Out. 2008.

MINISTÉRIO DA SAÚDE. Biblioteca Virtual em Saúde. Disponível em: <http://bvsms2.saude.gov.br/metaiah/search.php> Acesso em: 06. Out. 2008. 